\title{
Beneficial Preventive Effects of Gastric Mucosal Lesion for Soy-Skim Milk Fermented by Lactic Acid Bacteria
}

\author{
Chin-Feng Liu, ${ }^{\dagger}$ Chun-Ling Hu ${ }^{\S}$ Shen-Shin Chiang, ${ }^{\dagger}$ Kuo-Chuan Tseng, \\ Roch-Chui Yu, ${ }^{\S}$ and Tzu-Ming Pan*, \\ ${ }^{\dagger}$ Institute of Microbiology and Biochemistry, College of Life Science and ${ }^{\S}$ Institute of Food Science and \\ Technology, College of Bioresources and Agriculture, National Taiwan University, 1, Sec. 4, Roosevelt \\ Road, Taipei, Taiwan, Republic of China, and ${ }^{\#}$ Department of Food Science and Biotechnology, College \\ of Agriculture and Natural Resources, National Chung Hsing University, 250 Kuo Kuang Road, \\ Taichung, Taiwan, Republic of China
}

\begin{abstract}
In this study, Lactobacillus paracasei subsp. paracasei NTU101 and Lactobacillus plantarum NTU 102 were used as starter to ferment soy-skim milk, and the optimal mixing ratio was evaluated. The influence of lactic acid bacteria (LAB)-fermented soy-skim milk on mucosal integrity in a gastric mucosal lesion rat model was also investigated. After $24 \mathrm{~h}$, cell densities of $L$. paracasei subsp. paracasei NTU 101 and L. plantarum NTU 102 fermented in 75\% soy milk and 25\% milk (optimal condition) were $1.2 \times 10^{9}$ and $2.5 \times 10^{9} \mathrm{CFU} / \mathrm{mL}$. After 180 days at $4{ }^{\circ} \mathrm{C}$, the cell densities of the freeze-dried powders of the fermented soy-skim milks were $1 \times 10^{9} \mathrm{CFU} / \mathrm{g}$; slight variations in $\mathrm{pH}$ and acidity were observed. Pylorus ligation with acidified ethanol treatment was used as the gastric lesion animal model. LAB-fermented soy-skim milk reduced the gastric lesion index and the lipid peroxides (LPO) of gastric mucosa and serum. Administration of the fermented soy-skim milk enhanced superoxide dismutase (SOD) activity and prostaglandin $\mathrm{E}_{2}\left(\mathrm{PGE}_{2}\right)$ synthesis. Therefore, LAB-fermented soy-skim milk at $10^{9} \mathrm{CFU} /$ day protects against gastric injury.
\end{abstract}

KEYWORDS: Fermented soy-skim milk; acute gastric lesion; pylorus ligation combined with acidified ethanol

\section{INTRODUCTION}

Lactic acid bacteria (LAB) have health-promoting attributes, including antimutagenic and anticarcinogenic activities, hypocholesterolemic properties, and antagonistic actions that can restrain intestinal and foodborne pathogens and immunomodulation effects. LAB have been reported to improve gastrointestinal health. Furthermore, LAB and their fermented products can effectively enhance the integrity of the gastric mucosa. Many reports suggest that $\mathrm{LAB}$ and their fermented products have protective effects against mucosal injury in the stomach. Yogurt containing Lactobacillus gasseri OLL2716 (LG21 yogurt), which can enter the gastric mucus layer (1), has been shown to be effective in suppressing Helicobacter pylori and reducing gastric mucosal inflammation in humans (2). In 2004, Uchida and Kurakazu reported that the ingestion of LG21 yogurt by rats could increase prostaglandin $\mathrm{E}_{2}\left(\mathrm{PGE}_{2}\right)$ generation in the gastric mucosa, which led to the prevention of gastric ulcers (3). Lactobacillus rhamnosus GG (LGG) has also been reported to enhance gastric healing by activation of epidermal growth factor receptor (EGF receptor) and up-regulation of the expression of ornithine decarboxylase (ODC), B-cell lymphoma 2 (Bcl-2), and vascular endothelial growth factor (VEGF) in ulcerated tissues (4).

\footnotetext{
*Corresponding author (telephone $+886-2-33664519$, ext. 10; fax + 886-2-23627044; e-mail tmpan@ntu.edu.tw).
}

Soybeans are a source of dietary peptides, which have antihypertensive, anticholesterol, and antioxidative properties and may prevent various types of cancer. Soy milk is a traditional Chinese beverage made from soybean. Some reports have shown potential health benefits of ingesting soy milk in preventing and slowing the progression of prostate cancer (5).

Our laboratory has found two LAB strains native to Taiwan. These strains, Lactobacillus paracasei subsp. paracasei NTU 101 (6) and Lactobacillus plantarum NTU 102 (7), were isolated from human feces and homemade Korean-style cabbage pickles. These bacteria can resist gastric juice and bile salt. They also have probiotic characteristics that are effective in reducing cholesterol in the blood and liver (8). After ingestion of L. paracasei subsp. paracasei NTU 101, up-regulation of the antigen-presenting ability of dendritic cells and expression of natural killer group-2 D (NKG2D) molecules capable of triggering natural killer cellmediated cytotoxicity were observed. Lymphocyte proliferation and antibody production were also significantly increased in mice after treatment (9). Fermented soy-skim milk supplemented with or without Momordica charantia and L. paracasei subsp. paracasei NTU 101 is effective in preventing and slowing hyperlipidemia-induced oxidative stress and atherosclerosis (10). L. plantarum NTU 102 has also been shown to induce increased activity of superoxide dismutase (SOD) and phenol oxidase (PO) as part of the immune response to Litopenaeus vannamei (11). The aim of the present study was to investigate the antiulcer activity of 

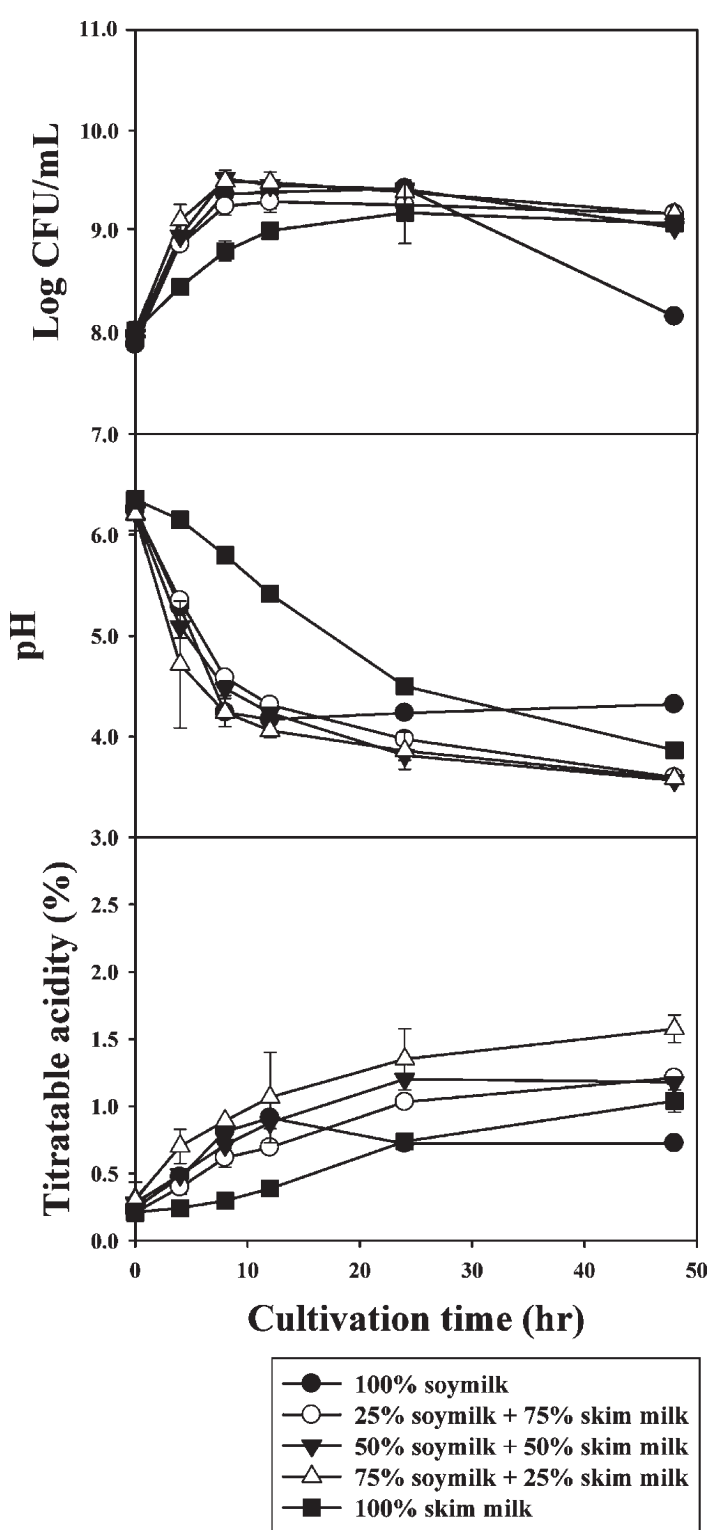

Figure 1. Growth of $L$. plantarum NTU 102 fermented with different ratios of soy milk and skim milk. Inoculum volume $=3 \%$; static incubation at $37^{\circ} \mathrm{C}$.

LAB-fermented soy-skim milk on the mucosal defense system. Pylorus ligation combined with acidified ethanol treatment was used as an animal model of gastric lesion.

\section{MATERIALS AND METHODS}

Chemicals and Media. Acetic acid, $n$-butanol, glycerol, histamine, indomethacin, methanol, o-phthaldehyde (OPA), sodium chloride, sodium dodecyl sulfate (SDS), and 1,1,3,3-tetramethoxypropane (TMP) were purchased from Sigma Chemical Co. (St. Louis, MO). Agar and gelatin digest peptone were purchased from Alpha Biosciences (Baltimore, MD). Lactobacilli MRS broth was purchased from Difco Co. (Detroit, MI).

Preparation of Soy-Skim Milk and Fermented Soy-Skim Milk by LAB and Analytical Assays. The preparation of soy-skim milk and fermented soy-skim milk by LAB was described as follows: Skim milk at $8 \%(\mathrm{w} / \mathrm{v})$ was reconstituted with Anchor skim milk powder (Fonterra Ltd., Auckland, New Zealand). The skim milk was treated individually in a water bath at $90^{\circ} \mathrm{C}$ for $1 \mathrm{~h}$. The nongenetically modified sugar-free soy milk was purchased from a local supermarket (Chuan Kui Yuba Factory, Taipei, Taiwan) and autoclaved for $15 \mathrm{~min}$ at $121{ }^{\circ} \mathrm{C}$ as described by Chou and Hou (12). After heat treatment and cooling to room temperature, skim milk and soy milk were mixed in various proportions of $0: 100,25: 75,50: 50,75: 25$, and 100:0, respectively.

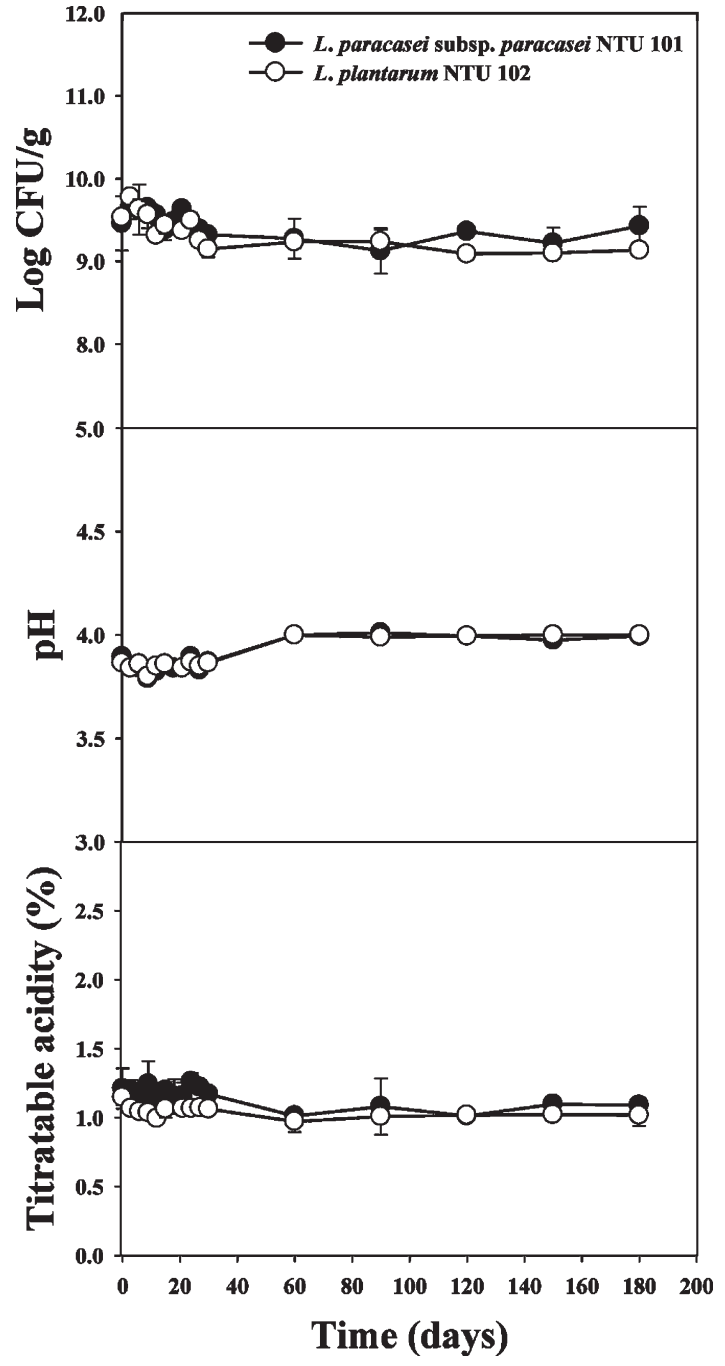

Figure 2. Shelf-life studies: changes of cell count, $\mathrm{pH}$ value, and titratable acidity in fermented soy-skim milk freeze-dried powder during the storage period. Medium, $75 \%$ soy milk $+25 \%$ skim milk; inoculum volume, $3 \%$; storage at $4{ }^{\circ} \mathrm{C}$.

L. paracasei subsp. paracasei NTU 101 and L. plantarum NTU 102 were inoculated at $1 \%$ on lactobacilli MRS broth and transferred monthly. Furthermore, these strains were inoculated in soy-skim milk at $37^{\circ} \mathrm{C}$ for $0-48 \mathrm{~h}$, respectively which was lyophilized by Bench Tops3R (Virtis Co., Gardiner, NY) and stored at $4{ }^{\circ} \mathrm{C}$ prior to use. During incubation, samples were taken at $0,4,8,12,24$, and $48 \mathrm{~h}$ for testing of $\mathrm{pH}$, culture growth, and titratable acidity. The $\mathrm{pH}$ of the sample was measured with a pH-meter (MP2000, Mettler Toledo, Greifensee, Switzerland). MRS agar was used to enumerate $L$. paracasei subsp. paracasei NTU 101 and L. plantarum NTU 102, respectively. Plates were incubated in an ordinary incubator at $37^{\circ} \mathrm{C}$ for 2 days. The colonies appearing on the plates were counted. Titratable acidity was determined using the method described in section 37.1.37 of AOAC, 1997.

Shelf-Life Studies. The shelf life of the fermented soy-skim milk with the highest mean score of overall acceptability was assessed. The freeze-dried powder of fermented soy-skim milk by LAB was stored at $4{ }^{\circ} \mathrm{C}$ for 6 months and then evaluated for $\mathrm{pH}$, culture viability, and titratable acidity.

Animal Grouping and Experiment Schedule. Male Wistar rats about 4 weeks of age were obtained from the Laboratory Animal Center of National Taiwan University, College of Medicine. They were kept in a temperature-controlled room $\left(25^{\circ} \mathrm{C}\right)$ with a maintained relative humidity of $60 \%$ under a $12 \mathrm{~h}$ light $/ 12 \mathrm{~h}$ dark cycle (light on at 9:00 a.m.). Food and water were given freely each day. The experiment was reviewed and approved by the Animal Care and Research Ethics Committee of the National Taiwan University. In the experiment, 56 rats were randomly 
Table 1. Effects of Gastric Acid Secretary Parameters and Gastric Lesion Index in Rats ${ }^{a}$

\begin{tabular}{|c|c|c|c|c|c|c|}
\hline \multirow[b]{2}{*}{ group } & \multicolumn{3}{|c|}{ gastric acid secretary parameters } & \multicolumn{3}{|c|}{ gastric lesion index } \\
\hline & $\mathrm{pH}$ & vol of gastric acid $(\mathrm{mL})$ & total gastric acidity (mequiv/L) & lesion area $\left(\mathrm{mm}^{2}\right)$ & total mucosal area $\left(\mathrm{mm}^{2}\right)$ & lesion index \\
\hline control & $3.84 \pm 0.15 a$ & $4.77 \pm 0.23 \mathrm{ab}$ & $35.25 \pm 2.94 a$ & $99.01 \pm 18.43 a$ & $977.99 \pm 65.14 a$ & $1.01 \pm 0.18 \mathrm{a}$ \\
\hline yogurt & $3.92 \pm 0.24 a$ & $3.28 \pm 0.32 d$ & $35.24 \pm 3.46 a$ & $70.02 \pm 12.14 a b$ & $991.75 \pm 40.01 a$ & $0.70 \pm 0.12 a b$ \\
\hline soy-skim milk & $3.60 \pm 0.12 \mathrm{ab}$ & $4.88 \pm 0.27 a b$ & $33.13 \pm 2.51 \mathrm{a}$ & $98.95 \pm 6.52 \mathrm{a}$ & $1010.33 \pm 46.62 a$ & $0.99 \pm 0.06 a$ \\
\hline $101-8$ & $3.71 \pm 0.18 \mathrm{ab}$ & $4.34 \pm 0.24 b c$ & $34.13 \pm 1.25 a$ & $84.83 \pm 12.47 a b$ & $1054.08 \pm 43.85 a$ & $0.80 \pm 0.11 a b$ \\
\hline $101-9$ & $3.12 \pm 0.13 b$ & $5.15 \pm 0.22 a$ & $34.50 \pm 3.15 a$ & $53.26 \pm 8.13 b$ & $993.42 \pm 45.77 a$ & $0.55 \pm 0.09 b$ \\
\hline $102-8$ & $3.66 \pm 0.24 a b$ & $3.81 \pm 0.22 \mathrm{~cd}$ & $36.75 \pm 3.02 \mathrm{a}$ & $72.89 \pm 13.36 a b$ & $998.60 \pm 39.74 a$ & $0.72 \pm 0.12 a b$ \\
\hline $102-9$ & $3.55 \pm 0.21 \mathrm{ab}$ & $3.83 \pm 0.27 \mathrm{~cd}$ & $33.13 \pm 2.04 a$ & $9.33 \pm 15.98 a b$ & $1098.40 \pm 26.40 \mathrm{a}$ & $0.66 \pm 0.14 a b$ \\
\hline
\end{tabular}

${ }^{a}$ Control, normal diet; yogurt, commercial yogurt diet; soy-skim milk, nonfermented soy-skim milk; $101-8,10^{8} \mathrm{CFU} /$ day of soy-skim milk fermented by L. paracasei subsp. paracaseiNTU $101 ; 101-9,10^{9} \mathrm{CFU} /$ day of soy-skim milk fermented by L. paracaseisubsp. paracaseiNTU $101 ; 102-8,10^{8} \mathrm{CFU} /$ day of soy-skim milk fermented by L. plantarum NTU $102 ; 102-9,10^{9} \mathrm{CFU} /$ day of soy-skim milk fermented by L. plantarum NTU 102. Data are presented as mean \pm SEM $(n=8)$; numbers with different letters within the same column are significantly different $(p<0.05)$.

divided to 7 groups including (1) administration of water (control), (2) administration of commercial yogurt (yogurt), (3) administration of nonfermented soy-skim milk (soy-skim milk), (4) administration of $10^{8} \mathrm{CFU} /$ day of soy-skim milk fermented by L. paracasei subsp. paracasei NTU 101 (101-8), (5) administration of $10^{9} \mathrm{CFU} /$ day of soy-skim milk fermented by $L$. paracasei subsp. paracasei NTU 101 (101-9), (6) administration of $10^{8} \mathrm{CFU} /$ day of soy-skim milk fermented by L. plantarum NTU 102 (102-8), and (7) administration of $10^{9} \mathrm{CFU} /$ day of soy-skim milk fermented by L. plantarum NTU 102 (102-9).

Rats were fed for 28 continuous days; $24 \mathrm{~h}$ before surgery and sacrifice, all food was removed. The animals were anesthetized by sodium pentobarbital (SCI Pharmtech, Taoyuan, Taiwan) and pylorus ligation (13) combined with acidified ethanol $(0.15 \mathrm{~N} \mathrm{HCl}$ and $70 \%$ ethanol mixture) (14) for $1 \mathrm{~h}$. Animals were euthanized by carbon dioxide inhalation. Gastric juices were collected, and their $\mathrm{pH}$, volume of gastric acid, and total gastric acidity were evaluated (13). The stomach tissue was cut open and cleaned frequently with $0.8 \%$ sodium chloride solution and examined for ulceration and damage by microscopic examination of a stomach biopsy. Gastric mucosa was collected on the surface of the stomach and stored at $-80{ }^{\circ} \mathrm{C}$ for the assay of SOD activity, thiobarbituric acid reactive substances (TBARS), and $\mathrm{PGE}_{2}$.

Determination of the Level of Mucosal SOD. The SOD activities of homogenate supernatant of gastric mucosa from rats were examined using the RANSOD commercial kit (Randox Laboratories Ltd., Crumlin, U.K.) (10).

Determination of the Level of Mucosal TBARS. TBARS levels of gastric mucosa were determined according to the method of thiobarbituric acid (TBA) colorimetric analysis, and the optical density (OD) value was measured at $532 \mathrm{~nm}$. Lipid peroxidation (LPO) in the supernatant of gastric mucosa homogenate was estimated in terms of TBARS with modification (15). TBARS level was expressed in nanomoles per gram of wet tissue. A standard curve was prepared by diluting well-known concentrations $(0,1.5625,2.5,3.125,6.25$, and $12.5 \mathrm{nmol} / \mathrm{L})$ of TMP in $0.01 \mathrm{~N} \mathrm{HCl}$.

Determination of the Level of Mucosal PGE2. Gastric mucosal tissues were homogenized and centrifuged, and the supernatant was used for $\mathrm{PGE}_{2}$ determination using a $\mathrm{PGE}_{2}$ enzyme immunoassay (EIA) kit (Amersham Bioscience, Little Chalf-ont, U.K.) according to the manufacturer's instruction. $\mathrm{PGE}_{2}$ level was expressed in picograms per milligram of protein, where the protein concentration was measured by NanoDrop 1000 spectrophotometer (Thermo Scientific) (16).

Study on Morphology and Histology of the Stomach. The morphology of the stomach was evaluated (17). Images were analyzed by ImageJ (ImageJ 1.38x, Rasband, WS; U.S. National Institutes of Health, Bethesda, MD), and the ulcer index was calculated by using the equation ulcer index $=10 / X$, where $X=$ total mucosal area/ulcerated area. Pathological tissues were entrusted to the Laboratory Animal Center of National Taiwan University, College of Medicine.

Statistics. Data are expressed as the mean \pm SEM. The statistical significance in the behavioral and biochemical effects was determined by one-way ANOVA, followed by ANOVA with Duncan's multiplerange tests.

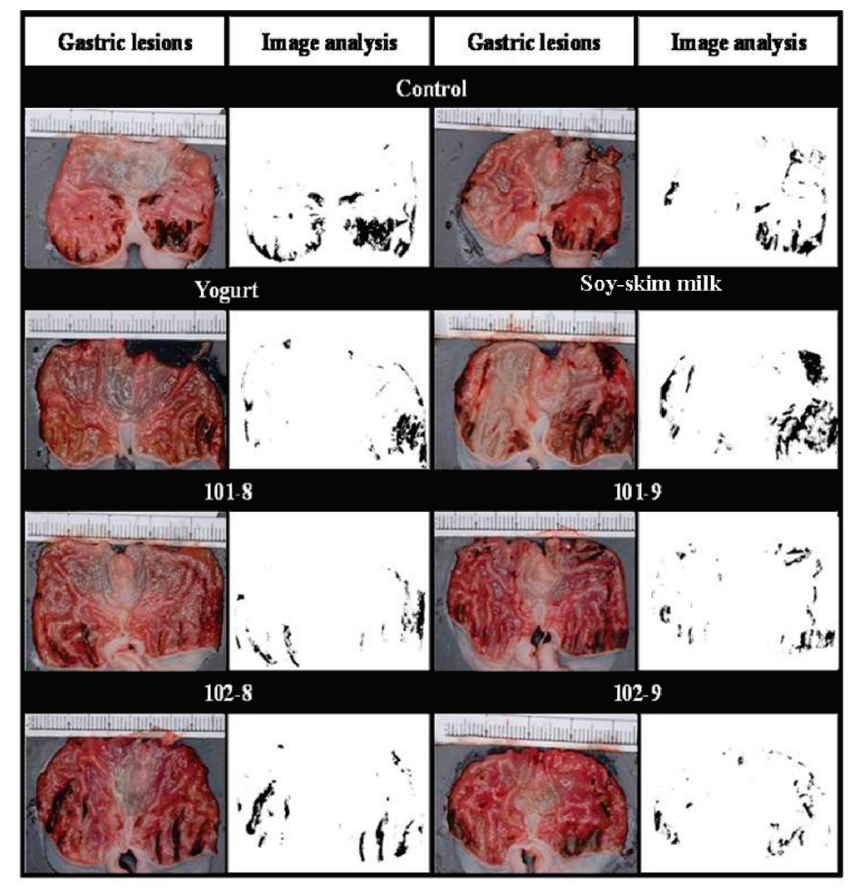

Figure 3. Image analysis of gastric lesion. Rats fed yogurt, soy-skim milk, and fermented soy-skim milk for 4 weeks after pylorus ligation combined with acidified ethanol induced acute gastric lesions of gastric mucosa (left); the same images after optimized background subtraction by ImageJ software (right).

\section{RESULTS}

Growth of $L$. plantarum NTU 102 Fermented in Soy-Skim Milk. After $24 \mathrm{~h}$ of fermentation with L. plantarum NTU 102, the titratable acidity of the mixture of $75 \%$ soy milk and $25 \%$ skim milk was highest of all the groups. The cell densities of each group were similar $\left(10^{9} \mathrm{CFU} / \mathrm{mL}\right)$ (Figure 1). We used the $75 \%$ soy milk and $25 \%$ skim milk mixture as the optimal medium for fermentation by L. plantarum NTU 102.

Shelf-Life Studies. The results of the shelf-life studies are shown in Figure 2. After storage for 180 days at $4{ }^{\circ} \mathrm{C}$, the cell densities in the freeze-dried powders of soy-skim milk fermented by L. paracasei subsp. paracasei NTU 101 and L. plantarum NTU 102 were at $1 \times 10^{9} \mathrm{CFU} / g$. There were slight variations in $\mathrm{pH}$ and titratable acidity. The samples were stable at $4{ }^{\circ} \mathrm{C}$.

Change in Body Weight and Daily Intake of Experimental Rats. The body weight and daily intake of the experimental rats increased normally and did not differ among the groups during the experiment (data not shown). In addition, the externals and health of all experimental animals had a normal expression. 


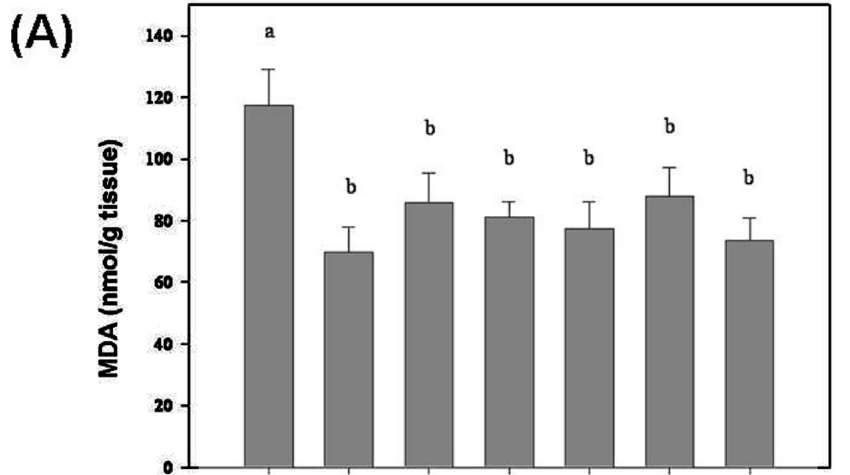

(B)

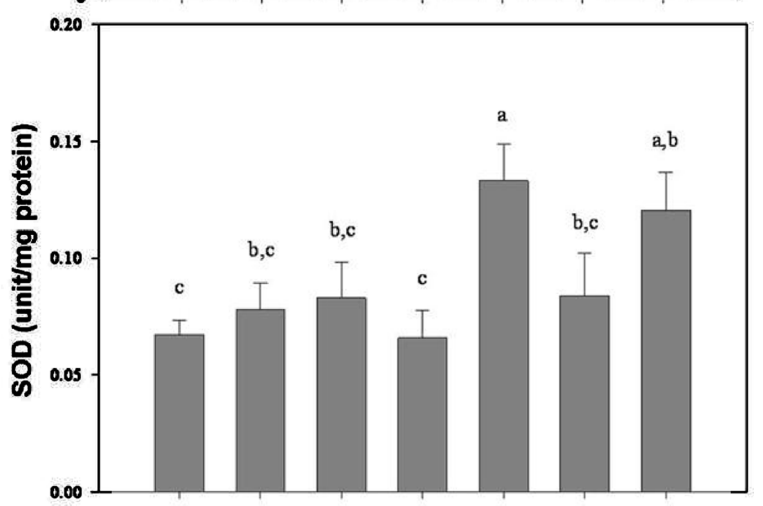

(C)

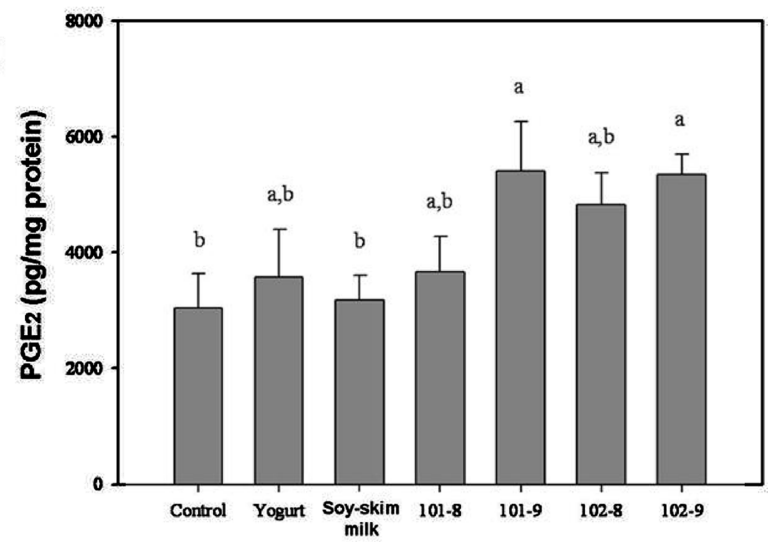

Figure 4. Changes of $L P O(\mathbf{A})$, SOD activity (B), and $P G E_{2}$ level $(\mathbf{C})$ of the gastric mucosa in rats fed yogurt, soy-skim milk, and soy-skim milk fermented by L. paracasei subsp. paracasei NTU 101 and L. plantarum NTU 102 for 4 weeks after pylorus ligation combined with acidified ethanol induced acute gastric lesions. Bars with different letters are significantly different $(p<0.05)$.

Gastric Acid Parameters and Gastric Lesion Index. Of all of the experimental groups, the gastric juice of the 101-9 group had the lowest $\mathrm{pH}(p<0.05)$ (Table 1). Feeding rats with soy-skim milk fermented with L. plantarum NTU 102 (102-8 and 102-9 groups) reduced the volume of gastric acid. The total gastric acidity was not different among groups $(p<0.05)$. With regard to the gastric lesion index, microscopical findings of the gastric mucosal are shown in Figure 3. The lesion indices in the control group and the nonfermented soy-skim milk group were not different $(p<0.05)$ (Table 1). Groups 101-8, 102-8, and 102-9 were not significantly different from the control group $(1.01 \pm 0.18)$. There was dose-dependent inhibition of acute gastric lesions in the 101-9 group, and significant differences were observed.

Effects of LAB-Fermented Milk on LPO and SOD Activities in the Gastric Mucosa. LPO activity was increased in the control group. Feeding with commercial yogurt, nonfermented
Liu et al.

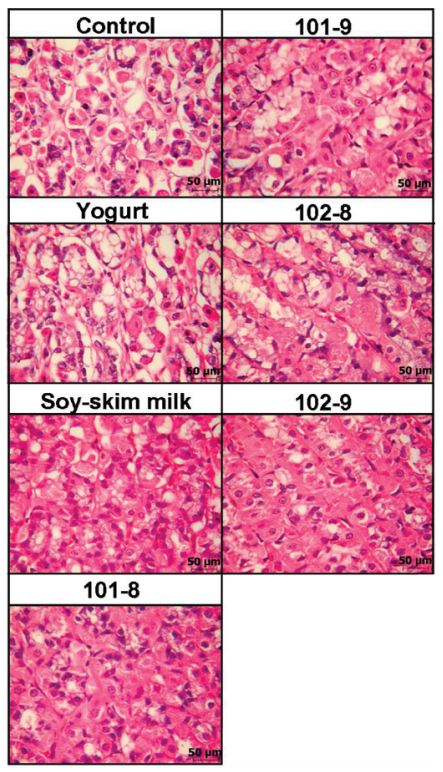

Figure 5. Histological studies of gastric mucosa of rats fed yogurt, soy-skim milk, and soy-skim milk fermented by L. paracaseisubsp. paracasei NTU 101 and L. plantarum NTU 102 for 4 weeks after pylorus ligation combined with acidified ethanol induced acute gastric lesions rats $(400 \times)$.

soy-skim milk, and fermented soy-skim milk (groups 101-8, 101-9, 102-8, and 102-9) reduced the level of LPO in the gastric mucosa (Figure 4A). SOD activity was decreased in rats that received pylorus ligation combined with acidified ethanol. There was no significant difference in SOD activity between the control group and the groups which received commercial yogurt or nonfermented soy-skim milk (101-8 and 102-8). In contrast, groups 101-9 and 102-9 had enhanced SOD activity in the gastric mucosa (Figure 4B).

Effects of LAB-Fermented Milk on $\mathrm{PGE}_{2}$ Generation in the Gastric Mucosa. In the control group, $\mathrm{PGE}_{2}$ generation in the gastric mucosa was $3036.16 \mathrm{pg} / \mathrm{mg}$ of protein. Groups 101-9 and 102-9 had significantly increased $\mathrm{PGE}_{2}$ generation (5408 and $5340 \mathrm{pg} / \mathrm{mg}$ of protein, respectively, $p<0.05$ ) (Figure 4C). Although there was no significant difference in biochemical analysis between group 101-8 and the control group, there was a trend of increasing levels of $\mathrm{PGE}_{2}$ in group 101-8.

Histological Study. Rats fed commercial yogurt and soy-skim milk fermented by L. paracasei subsp. paracasei NTU 101 and L. plantarum NTU 102 ( $10^{9} \mathrm{CFU} /$ day) had normal mucosal structure. Mucosal structures were significantly different in the group that received water or nonfermented soy-skim milk (Figure 5).

\section{DISCUSSION}

Stomach ulcers, a modern disease, are caused by regular smoking, use of alcohol, exposure to chemicals and toxic substances, and acid stress, all of which indirectly affect food digestion and absorption, functions that both have tremendous impact on human health (18). Recent studies in rats have shown that some foods, such as fruits and vegetables, have strong preventive effects on gastric ulcers induced by $\mathrm{HCl}$ or ethanol (19). Dairy foods are also recommended as therapy for patients with peptic ulcer. In 1984, Materia et al. reported that prostaglandins in milk may be responsible for its beneficial effects in the prevention of peptic ulcer in rats by using a cold-restraint stressinduced ulcer model (20). Dial and Lichtenberger demonstrated that milk and its phospholipids have antiulcer activity against acute gastric lesions induced by $0.6 \mathrm{M} \mathrm{HCl}(21)$. Furthermore, the 
lipid and nonlipid fractions of dairy foods possess gastroprotective activity against stress-induced ulcer in rats (22). In contrast, Ippoliti et al. reported that the proteins and calcium in milk, which stimulate gastric acid secretion, are not suitable for patients with peptic ulcer (23). However, milk has been reported to be effective for ulcer healing.

High intake of fermented milk products may decrease the risk for ulcer (24). LAB-fermented milk also has strong antiulcer properties on gastric lesions. In 2001, Sakamoto et al. reported that LG21 was effective in suppressing $H$. pylori and reducing gastric mucosal inflammation (2). Uchida and Kurakazu reported that LG21 yogurt significantly and dose-dependently inhibited the formation of acute gastric lesions caused by $0.6 \mathrm{M}$ $\mathrm{HCl}$ in rats (3). They also reported that $\mathrm{PGE}_{2}$ was significantly increased in the gastric mucosa (3). In human trials, LG21 strains administered through a yogurt drink have been reported to enter the gastric mucus layer and suppress $H$. pylori colonization in the stomach (1). In 2007, Lam et al. suggested that LGG could attenuate ethanol-induced apoptosis and enhance gastric ulcer healing (4). LGG has also been reported to stimulate mucus secretion and increase transmucosal resistance in the gastric mucosa (25).

Soy milk, a traditional food that has been used in China for thousands years, has been reported to be an antacid that can neutralize gastric juice to a $\mathrm{pH}$ above 3.0 (26). In our study, continuously feeding LAB-fermented soy-skim milk to rats for 28 days inhibited acute gastric lesions induced by pylorus ligation combined with acidified ethanol in a dose-dependent manner. However, nonfermented soy-skim milk, which is composed of the same raw materials except for $\mathrm{LAB}$, had no significant effect on the gastric ulcer healing.

Oxidative stress could initiate and aggravate many diseases, including peptic ulcers and gastric carcinoma (27). The activities of SOD and catalase have a specific role in protecting the gastric mucosa against oxidative damage (28). Oral administration of acidified ethanol significantly increased the level of LPO in the gastric mucosa and decreased the activity of antiperoxidative enzyme. Except for the control group, the level of LPO was significantly decreased in each group. Groups 101-9 and 102-9 significantly enhanced the level of SOD activity in acute lesions in rats caused by pylorus ligation combined with acidified ethanol.

In 1998, Elliott et al. reported that bacteria rapidly colonize and modulate healing of gastric ulcers in rats. Gram-negative bacteria are likely responsible for the observed delay in ulcer healing, whereas Gram-positive bacteria may actually promote ulcer healing (29). However, soy-skim milk fermented with LAB is a natural food devoid of any side effects, and it is a novel alternative medicine for the prevention of gastric ulceration disease.

This is the first report that used pylorus ligation combined with acidified ethanol to establish gastric ulceration in an animal model. In previous studies, we used different models of acute gastric lesion, including chemical reagents $(0.6 \mathrm{~N} \mathrm{HCl}, 60 \%$ ethanol, and $0.15 \mathrm{M} \mathrm{HCl}+70 \%$ ethanol) combined with pylorus ligation to compare the experimental time, status of the lesion, operative convenience, and deviation. Pylorus ligation combined with acidified ethanol is more appropriate to use as an experimental model (data not shown).

In summary, a 75:25 ratio of soy milk to skim milk fermented with L. paracasei subsp. paracasei NTU 101 or L. plantarum NTU 102 is useful for the prevention of acute gastric ulcers induced by pylorus ligation and acidified ethanol treatment through $\mathrm{PGE}_{2}$ and significantly enhanced the level of SOD activity. These findings may indicate that LAB-fermented soy-skim milk is useful for the prevention of gastric ulcers.

\section{LITERATURE CITED}

(1) Fujimura, S.; Kato, S.; Oda, M.; Miyahara, M.; Ito, Y.; Kimura, K.; Kawamura, T.; Ohnuma, M.; Tateno, H.; Watanabe, A. Detection of Lactobacillus gasseri OLL2716 strain administered with yogurt drink in gastric mucus layer in humans. Lett. Appl. Microbiol. 2006, 43, 578-581.

(2) Sakamoto, I.; Igarashi, M.; Kimura, K.; Takagi, A.; Miwa, T.; Koga, Y. Suppressive effect of Lactobacillus gasseri OLL 2716 (LG21) on Helicobacter pylori infection in humans. J. Antimicrob. Chemother. 2001, 47, 709-710.

(3) Uchida, M.; Kurakazu, K. Yogurt containing Lactobacillus gasseri OLL2716 exerts gastroprotective action against acute gastric lesion and antral ulcer in rats. J. Pharmacol. Sci. 2004, 96, 84-90.

(4) Lam, E. K. Y.; Yu, L.; Wong, H. P. S.; Wu, W. K. K.; Shin, V. Y.; Tai, E. K. K.; So, W. H. L.; Woo, P. C. Y.; Cho, C. H. Probiotic Lactobacillus rhamnosus GG enhances gastric ulcer healing in rats. Eur. J. Pharmacol. 2007, 565, 171-179.

(5) Jacobsen, B. K.; Knutsen, S. F.; Fraser, G. E. Does high soy milk intake reduce prostate cancer incidence? The Adventist Health Study (United States). Cancer Causes Control 1998, 9, 553-557.

(6) Lin, F. M.; Chiu, C. H.; Pan, T. M. Fermentation of a milk-soymilk and Lycium chinense Miller mixture using a new isolate of Lactobacillus paracasei subsp. paracasei NTU101 and Bifidobacterium longum. J. Ind. Microbiol. Biotechnol. 2004, 31, 559-564.

(7) Pan, T. M.; Chiu, C. H.; Guu, Y. K. Characterization of Lactobacillus isolates from pickled vegetables for use as dietary or pickle adjuncts. Foods Food Ingred. J. Jpn. 2002, 206, 45-51.

(8) Chiu, C. H.; Lu, T. Y.; Tseng, Y. Y.; Pan, T. M. The effects of Lactobacillus-fermented milk on lipid metabolism in hamsters fed on high-cholesterol diet. Appl. Microbiol. Biotechnol. 2006, 71, $238-245$.

(9) Tsai, Y. T.; Cheng, P. C.; Fan, C. K.; Pan, T. M. Time-dependent persistence of enhanced immune response by a potential probiotic strain Lactobacillus paracasei subsp. paracasei NTU 101. Int. J. Food Microbiol. 2008, 128, 219-225.

(10) Tsai, T. Y.; Chu, L. H.; Lee, C. L.; Pan, T. M. Atherosclerosispreventing activity of lactic acid bacteria-fermented milk-soymilk supplemented with Momordica charantia. J. Agric. Food Chem. 2009, 57, 2065-2071.

(11) Chiu, C. H.; Guu, Y. K.; Liu, C. H.; Pan, T. M.; Cheng, W. Immune responses and gene expression in white shrimp, Litopenaeus vannamei, induced by Lactobacillus plantarum. Fish Shellfish Immunol. 2007, 23, 364-377.

(12) Chou, C. C.; Hou, J. W. Growth of bifidobacteria in soymilk and their survival in the fermented soymilk drink during storage. Int. J. Food Microbiol. 2000, 56, 113-121.

(13) Shay, H.; Komarov, S. A.; Fels, S. S.; Meranze, D.; Grunstein, N.; Siplet, H. A simple method for the uniform production of gastric ulceration in the rat. Gastroenterology 1945, 5, 43.

(14) Hara, N.; Okabe, S. Effects of gefarnate on acute gastric lesions in rats. Nippon Yakurigaku Aasshi. 1985, 85, 443-446.

(15) Ohkawa, H.; Ohishi, N.; Yagi, K. Assay for lipid peroxides in animal tissues by thiobarbituric acid reaction. Anal. Biochem. 1979, 91 351-358.

(16) Desjardins, P.; Hansen, J. B.; Allen, M. Microvolume spectrophotometric and fluorometric determination of protein concentration. Curr. Protoc. Protein Sci. 2009, Chapter 3, Unit 3.10.

(17) Shewade, Y.; Umarani, M.; Bhonde, R. R. Large-scale isolation of islets by tissue culture of adult mouse pancreas. Transplant. Proc. 2001, 31, 1721-1723.

(18) Kato, I.; Nomura, A. M.; Stemmermann, G. N.; Chyou, P. H. A prospective study of gastric and duodenal ulcer and its relation to smoking, alcohol, and diet. Am. J. Epidemiol. 1992, 135, 521-530.

(19) Hamauzu, Y.; Inno, T.; Kume, C.; Irie, M.; Hiramatsu, K. Antioxidant and antiulcerative properties of phenolics from Chinese quince, quince, and apple fruits. J. Agri. Food Chem. 2006, 54 765-772.

(20) Materia, A.; Jaffe, B. M.; Money, S. R.; Rossi, P.; De Marco, M.; Basso, N. Prostaglandins in commericial milk preparations. Their effect in the prevention of stress-induced gastric ulcer. Arch. Surg. 1984, 119, 290-292. 
(21) Dial, E. J.; Lichtenberger, L. M. Milk protection against experimental ulcerogenesis in rats. Dig. Dis. Sci. 1987, 32, 1145-1150.

(22) Dial, E. J.; Romero, J. J.; Lichtenberger, L. M. Gastroprotection by dairy foods against stress-induced ulcerogenesis in rats. Dig. Dis. Sci. 1995, 40, 2295-2299.

(23) Ippoliti, A. F.; Maxwell, V.; Isenberg, J. I. The effect of various forms of milk on gastric acid secretion. Ann. Intern. Med. 1976, 84, 286-289.

(24) Elmstahl, S.; Svensson, U.; Berglund, G. Fermented milk products are associated to ulcer disease. Results from a cross-sectional population study. Eur. J. Clin. Nutr. 1998, 52, 668-674.

(25) Lam, E. K.; Tai, E. K.; Koo, M. W.; Wong, H. P.; Wu, W. K.; Yu, L.; So, W. H.; Woo, P. C.; Cho, C. H. Enhancement of gastric mucosal integrity by Lactobacillus rhamnosus GG. Life Sci. 2007, 80 2128-2136.
(26) Fung, W. P.; Tye, C. Y. Evaluation of soya bean milk as an antacid. Singapore Med. J. 1973, 14, 515-518.

(27) Tandon, V.; Gupta, R. K. Histomorphological changes induced by Vitex negundo in albino rats. Indian J. Pharmacol. 2004, 36 $176-177$.

(28) Anandan, R.; Nair, P. G.; Mathew, S. Anti-ulcerogenic effect of chitin and chitosan on mucosal antioxidant defence system in $\mathrm{HCl}-$ ethanol-induced ulcer in rats. J. Pharm. Pharmacol. 2004, $56,265-269$.

(29) Elliott, S. N.; Buret, A.; McKnight, W.; Miller, M. J.; Wallace, J. L. Bacteria rapidly colonize and modulate healing of gastric ulcers in rats. Am. J. Physiol. 1998, 275, G425-G432.

Received for Review February 9, 2009. Revised manuscript received March 27, 2009. Accepted March 29, 2009. 